Journal of Al Azhar University Engineering Sector

Vol. 13, No. 49, October, 2018, 1608-1616

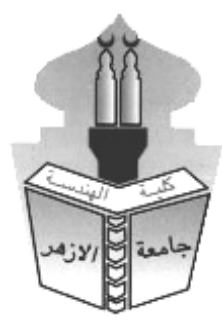

\title{
THE POTENTIAL OF RESIDENTIAL ENERGY STANDARDS IN EGYPT: A COMPARATIVE STUDY WITH THE CODE FOR SUSTAINABLE HOMES
}

\author{
Wael Sheta \\ Architecture Department, Al-Azhar University, Cairo, Egypt
}

\begin{abstract}
Building energy standards are the minimum requirements for energy-efficient design and construction for new and renovated residential and commercial buildings. Standards can have a major role in enhancing the thermal behavior of the building by providing the appropriate guidelines and recommendations for each particular community. This was the motivation in issuing the Egyptian Energy Code for Residential Buildings (EECRB) which were presented by Housing and Building National Research Centre in Egypt (HBNRC) in 2006. These standards relied on valuable studies carried out by the center in 2000, aiming to achieve a better performance and thermal comfort for the occupiers. However, materials and recommendations for these standards did not enter the framework of implementation so far. Articles of the Egyptian Construction Law issued in 2008 did not include any clause or reference to these standards, as the building regulations for new communities did mention neither materials nor recommendations of Egyptian energy standards. Can Egyptian energy standards help to maintain a quality indoor environment for residential buildings for existing and new urban communities is the question this study seeks to address. This study explores the current situation, with a preliminary analysis of how the (EECRB) may not be able to deliver its 'sustainable energy standards' goals due to the ways in which 'thermal behavior and building performance' are assessed and how they behave in real world situations. A comparative study with the Code for Sustainable Homes (CSH) in the UK has been done. The study demonstrates that further research, policy changes and practical improvements are needed to deliver sustainable energy for existing and new urban communities. More comprehensive guidelines should be given to designers to ensure the delivery of sustainable buildings is not hampered whilst also failing to meet energy standard goals.
\end{abstract}

\section{KEYWORDS : Energy standards, Energy-efficient design, Building code, Residential buildings, Sustainablebuildings.}

\section{INTRODUCTION}

Building codes address many of a society's most important concerns, including public health and safety, and environmental protection. Building codes also address cost efficiency and investment value. In large part, building codes establish a building's quality, safety and energy performance for years to come, because initial design and construction decisions determine operational and maintenance costs for the life of the building. Building equipment and other components may be replaceable and upgradeable, but many aspects of building performance are "designed in" at the beginning, and are too expensive and difficult to change. People spend nearly 90 percent of their lives inside buildings, according to the U.S. Environmental Protection Agency, which is clarify why building codes and design decisions have major impacts on buildings' users. Some 
requirements such as fire safety codes and structural standards affect users in obvious ways. Others, such as energy standards including thermal performance, lighting quality, acoustics and indoor air quality also have major effects on health and productivity.

Building energy standards (BES), is a set of minimum requirements for building design, construction and operation to protect public health, safety and the natural resources that sustain users, help them "build it right" at the beginning when it matters most. BES can now offer enhanced protection against the threats of natural disasters and terrorism to make our communities more resilient, sustainable and livable for generations to come. BES provide guidance on how to design, build and operate buildings to achieve these goals. They also provide an insurance industry grappling with the effects of climate change and extreme weather with a baseline for estimating and managing risk. This helps to control or lower the cost of insurance premiums (Evans et al., 2017). But BES are effective only if they are enacted into law and enforced by state and local governments or authorities.

Buildings consume vast amounts of natural resources, accounting for about 50 percent of total energy consumption in Egypt (Hanna, 2013). Therefore, BES that produce more valuable guidelines should benefit builders in addition to owners. On the residential side, the relatively small percentage increase in construction costs for homes built under BES is more than offset by improved quality and safety. Likewise, a home costing less to own and operate should produce a higher return at sale and resale. The new BES are making a major contribution toward solving energy and environmental problems. The average residential building in Egypt wastes far too much energy because it was not designed and constructed with energy efficiency as a priority. This is unacceptable especially with the increase in energy prices and the abolition of subsidies expected through the near future in Egypt. Furthermore, this is inappropriate at a time when best practices for sustainable design are widely known and taught, when energy efficient appliances and equipment are a growing percentage of suppliers' and retailers' inventories, and given the multiple benefits of reducing energy consumption of buildings.

\section{Code, Standard and Specification}

There are many differences between code, standard and specification terms that must be highlighted when "code" or "Standard" as a term is addressed in this study. Standard can be defined as a set of technical definitions and guidelines - or simply a "how to" instructions for designers and manufacturers. It gives all the necessary requirements for the product, service, and operation. A designer will use the standard to design the product, and a manufacturer will use the standard for the manufacturing of the product. Standard serves as a common language for defining quality and establishing safety criteria for the product. But when governmental bodies or authorities adopt the standard and become legally enforceable, or when it has been incorporated into a business contract, the standard will become a "code". This simply the difference between "Standard" and "code". Specifications provide specific or additional requirements for the materials, components or services that are beyond the code or standard requirements. Specification is generated by private companies and engineering firms to address additional requirements applicable to a specific product or application. Table 1 summarizes the differences between these terms. 
THE POTENTIAL OF RESIDENTIAL ENERGY STANDARDS IN EGYPT: ACOMPARATIVE STUDY WITH THE CODE FOR SUSTAINABLE HOMES

Table 1: Differences between Code, Standard and Specification

\begin{tabular}{|l|l|l|l|}
\hline & Code & Standard & Specification \\
\hline Enforcement & $\begin{array}{l}\text { Enforceable by law or by } \\
\text { contract }\end{array}$ & $\begin{array}{l}\text { Globally accepted "How } \\
\text { to instruction" }\end{array}$ & $\begin{array}{l}\text { Must meet requirements } \\
\text { by contacts }\end{array}$ \\
\hline Written by & $\begin{array}{l}\text { Government or } \\
\text { government approved } \\
\text { body }\end{array}$ & $\begin{array}{l}\text { Public organization or by } \\
\text { government body }\end{array}$ & Private companies \\
\hline Definition & $\begin{array}{l}\text { Guidelines for design, } \\
\text { and installation }\end{array}$ & $\begin{array}{l}\text { Set of technical } \\
\text { definitions and guideline } \\
\text { for manufacturing or } \\
\text { constructing }\end{array}$ & $\begin{array}{l}\text { Additional requirements, } \\
\text { beyond code and standard }\end{array}$ \\
\hline Example & Building codes & $\begin{array}{l}\text { Energy standards } \\
\text { Sustainable standards }\end{array}$ & $\begin{array}{l}\text { Specs associated with } \\
\text { tender documents }\end{array}$ \\
\hline
\end{tabular}

\section{BUILDING ENERGY CODES AND STANDARDS}

In the past decade, building environmental assessment methods have emerged in many parts of the world as a legitimate means to evaluate the performance of buildings across a broad range of environmental issues. One of the major challenges for building environmental assessment is to place building performance within a wider context of environmental sustainability. To assess the environmental sustainability of buildings, a number of technological, ecological and sociocultural factors are involved. The building's energy performance is usually the key element in the evaluation process and will constitute a significant portion of the overall assessment results. With growing interest and importance of BES in many worldwide locations, it is possible to make use of the requirements in the BES to support the sustainability assessment of buildings. In order to do that effectively, the nature and characteristics of the codes must be understood and the trends of code development have to be considered.

\subsection{Code for Sustainable Homes (CSH)}

The British Code for Sustainable Homes (CSH) was first introduced in 2007 as a discretionary national standard developed as a step towards achieving sustainable building practice for new and retrofitted homes. A number of government institutions were consulted during the process of preparing $\mathrm{CSH}$ including British Research Establishment (BRE), Construction Industry Research and Information Association (CIRIA) and Senior Steering Groups consisting of Government, industry and NGO representatives. The main objective of the CSH is to achieve sustainable home building while driving continuous improvement and greater innovation in the building industry (Al-Hassan, 2009). In 2008 both building codes and building regulations became mandatory and prior to May 2008 only building regulations were mandatory. The UK building regulations are the source of technical building information. The code of practice relates to specific aspects of the design and production of the building and civil engineering construction in harmony with the EU standards. The code became legally binding in May 2008. New amendments were made in the CSH based on feedback received from Code for Sustainable Home assessors, developers and wider industry stakeholders, and new versions published in October 2008 and then in November 2010. The Code service providers offer a range of services including assessor training, registration and monitoring, quality assurance of assessments, certification, investigation and resolution of complaints, and maintenance of records. The Codes of Sustainable Homes are applied in two stages; Design Stage (DS) when the building is at a design phase prior to construction, and Post Construction Stage (PCS) at the end of the construction phase in which evidence is shown of realizing all the information provided in the design stage such as the use of energy efficient products or certain building materials, etc. (Al-Hassan, 2009) (Ganah et al., 2015) (BRE, 2010) (McManus et al., 2010). 


\subsection{Energy Efficient Code (EEC)}

The Egyptian Code for Energy Efficient Buildings was first introduced in 2006 and was oriented to residential buildings followed by commercial buildings in 2007 and governmental buildings in 2010. These three versions of Energy Efficient Code (EEC) were the fruit of extensive studies done by the Housing and Building National Research Centre (HBNRC) in Egypt since 2000 (Sheta and Sharples, 2010). The Ministry of Housing and (HBNRC) intend to promulgate the residential and commercial codes as a mandatory section of the overall Building Code (HBNRC, 2007). In order to ensure the success of a planned wide-spread compliance with the code, HBNRC organized many programs to implement the code. These programs take many years and include such activities as developing compliance forms and procedures, in addition to enforcement inspection procedures and checklists. Moreover, create appropriate energy code administration structure with the authority, staffing, and technical support applying the Egyptian energy code (Hanna, 2013). The Egyptian Energy Code for Residential Buildings (EECRB) be considered as a step forward to achieving sustainability in residential buildings sector, it specifies minimum building requirements to improve both thermal and visual comfort in non-conditioned buildings as well as conditioned buildings. The code gives minimum performance standards for building windows and openings, natural ventilation and thermal comfort, ventilating and air conditioning equipment, natural and artificial lighting and electric power. A great effort has been made to ensure its applicability in residential buildings sector in Egypt (Hanna, 2004).

\section{LITERATURE REVIEW}

A large and growing body of literature has systematically and comprehensively reviewed implementation of BES across countries on both local and international scale. Baniassadi et al. (2018) investigated the role of evolving building energy codes aiming to understand how the evolution of energy codes affects the resiliency of buildings to heat. Whole-building energy simulations were undertaken to high-rise residential apartment buildings under a three-day power outage scenario with a three-day heat wave. Results showed that in most climate, indoor conditions exceed critical thresholds during modeled scenario. The observed increase in frequency and intensity of hot weather events in urban areas around the world and research that suggests a more extreme future, the resiliency of the built environment to heat has become a major concern for planners and policymakers. Chan (2018) evaluated the impact of solar panel devices on thermal performance of buildings and its implication to building energy code in subtropical climates. Three exciting buildings were used as a case study. It was found that solar panel devices have a significant effect in reducing heat gain ranging from $14 \%$ to $38 \%$. It was recommended to incorporate the effect of solar panel devices into the overall thermal transfer value regulation and to other building certificate schemes and energy codes. McManus el at. (2010) studied the current situation with preliminary analysis of how the code for sustainable homes in the UK may not be able to deliver its sustainable energy goals due to the way in which low and zero carbon technologies are assessed and how they behave in real world situation. Results indicated that further research and policy changes are needed to deliver sustainable energy for residential sector and ensure the delivery of new housing is not hampered whilst also failing to meet energy goals.

Enker and Morrison (2017) examined the application of socio-technical transition theory to the residential building sector with Australian energy policy as a case study. Evolution of building energy efficiency standards through the Australian national construction code is scrutinized by benchmarking the building energy against international best practice. Results provided a twofold contribution to research in the domain of building energy policy by making the connection between transition theory and the role of building energy code, and by demonstrating the practical application and utility of a structured building code benchmarking process. O'Malley et al. (2014) carried out a cross- sectional study to evaluate the efficacy of the code of sustainable homes $(\mathrm{CSH})$ in the UK. The study attempted to map (CSH) against LEED and CASBEE aiming 
to encourage assessment beyond physical boundaries of a building and into its immediate context and surrounding environment. A critical review of the latest literature was conducted to establish the general concepts and principles behind (CSH) following this, differences, positive and negative aspects of the three assessment methods were established through review of their official documents and by cross-referencing the different components, methodologies and assessment criteria of each.

Evans et al. (2017) (2018) demonstrated the international implications of the national and local coordination on building energy codes. Building energy code implementation in six cities across different continents were used as case studies to assess what it may take for countries to implement the ambitions of their energy efficiency goals. The study focused on understanding the baseline with existing gaps in implementation and coordination. The methodology used a combination of surveys on code status and interview with stakeholders at the local and national level, as well as review of published documents. Results provided examples of practices that countries have adopted to assist with implementation of building energy codes. Ganah et al. (2015) studied the feasibility of the government achieving its objective of all new housing having a zero carbon rating by 2016, through the implementation of (CSH). Findings identified barriers that prevent the UK housing sector from achieving zero carbon housing, including cost, legislative, cultural and technical impediments. Many studies focused on the Egyptian context; Hanna (2015) investigated green pyramid rating system and the potential of energy efficiency, renewable energy and green building codes to reduce depends of the fossil fuel in Egypt. The aim was to introduce the Egyptian efforts to improve the quality of life and highlight the barriers facing residential sector to deliver more sustainable buildings.

\section{MATERIAL AND METHODS}

Building energy codes are instruments that guide and specify the direction for improving energy efficiency practices. Legislations can take the form of regulations, guidelines, standards, codes, and others. They may call for voluntary or mandatory actions. Countries can implement codes with various levels of stringency: voluntary codes, mandatory codes, or some mixture depending on the region or state. This stringency metric is a basic reporting of the status of the building codes in a country. In Egypt, the national government does not have authority to pass mandatory building codes. Articles of the Egyptian unified building Law number 119 issued in 2008 and it executive appendix ministerial decree number 144 issued in 2009 did not include any clause or reference to these standards (Ayyad and Gabr, 2012), as the building regulations for new communities did mention neither materials nor recommendations of Egyptian energy standards. In contrast, the UK create mandatory building energy codes that cover the entire country (Young, 2014). For this study, we look at the comprehensiveness of the building codes for both countries.

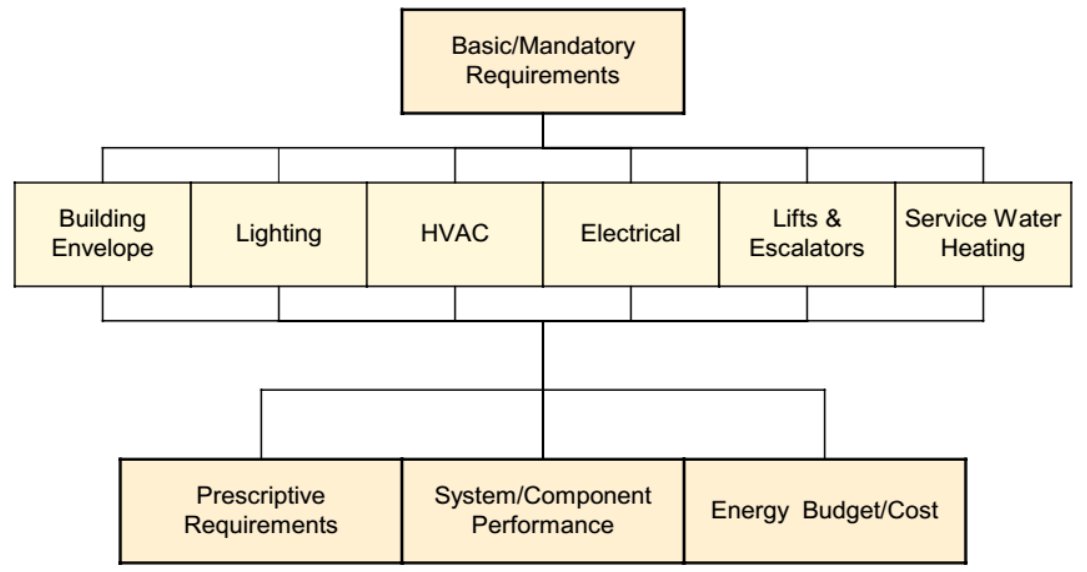

Figure 1: Major areas and compliance options for building energy codes (after Young, 2014). 
Figure 1 shows some major areas and compliance options of building energy codes. The major areas include building envelope, lighting, HVAC (heating, ventilating and air-conditioning), electrical power, lifts \& escalators and service water heating. The basic/mandatory requirements are fundamental issues that must be satisfied. The prescriptive requirements, system/component performance and energy budget/cost are the options available for meeting the code's other criteria. For example, prescriptive requirements may be the insulation levels for building envelope components or equipment efficiencies for lighting and HVAC systems. The system/component performance requirements try to combine the consideration of several parameters and provide "trade-off" among them in the compliance process, such as the calculation of overall thermal transmission. The energy budget/cost method offers the greatest flexibility to manipulate the design parameters since it considers in its evaluation the total energy consumption for the building as a whole. Compliance through the energy budget/cost option will need to study and estimate the likely consumption levels based on the integrated performance of the areas concerned. Since the energy budget/cost method is complicated and demanding, it is usually done by computer simulation and modelling. This study compares the EECRB against $\mathrm{CSH}$ the in the UK which come as a result of development in the international sustainability policy; consequently this study will assess the major components or criteria of BES, CSH and their use in new developments. The study will conclude with a review of the positive outcomes of the Egyptian code on the sustainable energy standards. This will include policy changes, proposed practical improvements and strategies amid to at achieving sustainability targets

\section{DISCUSSION AND CONCLUSION}

It is apparent from the comparative study that Egypt is still in the process of implementing the EECRB, whereas the UK has been much more successful in achieving their energy efficiency targets or has made more effective energy regulations. However, it could be claimed that Egypt succeeded in progressing towards realizing sustainable architecture. The Code for Sustainable Homes CSH was more comprehensive and all its categories is weighted according to scoring points system. CSH determined nine sustainability categories including energy and $\mathrm{Co} 2$ emissions, water, materials, surface water run-off, waste, pollution, health and well-being, management and ecology. The weight factor of these categories is 36.4, 9.0, 7.2, 2.2, 6.4, 2.8, $14.0,10.0,12.0 \%$ respectively. That clearly clarifies why it can be considered as a detailed-points scoring system not only energy standards. The Egyptian Energy Code for Residential Buildings (EECRB) comprises nine chapters including scope and compliance, general requirements, building envelope, natural ventilation and thermal comfort, heating ventilation and air conditioning, service water heating system, lighting, electrical power, whole building performance, in addition to definition, abbreviation and acronyms chapter. Despite both codes covered many practical examples in their parts, and many mandatory requirements as shown in Table 2, EECRB did not apply scoring points for each chapter and there is a lack in dealing with existing, renovated and retrofitted buildings, so that more comprehensive guidelines should be included in EECRB to feed designers with the importance and influence of each category on building energy performance to ensure the delivery of sustainable buildings goals. Moreover, there is a lack in communication between all parts of design and construction process; there is no mention of the feedback received from designers, developers and wider stakeholders.

In terms of stringency and coverage, $\mathrm{CSH}$ is well established and mandatory in most of its categories and cover many types of residential buildings, while the EECRB can be considered as a voluntary code and it was not clear the type of residential buildings this code should cover. For the technical requirements, the study analyzed that insulation of building envelope, window $\mathrm{u}-$ factor and shading, solar heat gain coefficient, lighting efficiency, heating and cooling requirements, technical installations were coved in both codes. Design requirements including architectural programming requirements for all the functions in the building and their relationship to one another, including energy efficiency targets, primary functions, occupancy and time of use, 
daylight potential and electric light requirements, indoor environmental quality standards, equipment and plug loads, acoustic quality, and safety and security, are still missing or neglected in EECRB and should be added and highlighted in updated versions. Moreover, prescriptive requirements and energy budget/cost method should be considered as it offers the greatest flexibility to manipulate the design parameters in the initial phase of design. Table 3 highlighted some of voluntary requirements of energy codes.

Table 2: Basic/mandatory requirements.

\begin{tabular}{|l|l|l|}
\hline & EECRB & CSH \\
\hline Building envelope & & \\
\hline Lighting & & \\
\hline HVAC & & \\
\hline Natural Ventilation & & \\
\hline Sound Insulation & & \\
\hline Electrical & & \\
\hline Waste management & & \\
\hline Service water heating & & \\
\hline CO2 emission & & \\
\hline Rating scoring system & & \\
\hline
\end{tabular}

Table 3: Non mandatory (Voluntary) requirements.

\begin{tabular}{|l|l|l|}
\hline & EECRB & CSH \\
\hline Prescriptive requirements & & \\
\hline System/component performance & & \\
\hline Energy budget/cost & & \\
\hline
\end{tabular}

Ensuring the most effective enforcement of building codes is challenging for many countries because often the responsibility lies with local governments that may be understaffed and underfunded. In addition, it is difficult to obtain data on the levels of enforcement in each country for similar reasons. However, many efficiency experts agree that enforcement is one of the most important elements to the building energy code because it ensures compliance and effective savings. In addition, many countries have implemented incentives and disincentives to help push contractors and home builders to comply with the codes. In this study, an attention is given to capture these efforts and shine a light on some of the most robust policy packages. The authorities in the UK agree that enforcement is one of the most challenging aspects of building energy codes, but one of the most important aspects of ensuring that codes are implemented and savings are realized. So that they couple building energy codes with incentives and robust policy packages, such as local enforcement, accreditation of applicants, post-occupancy control, energy performance certificates, positive labeling for building beyond the minimum building code level, energy offsets/green certificates. Similar incentives should be implemented and coupled with energy efficient codes in Egypt, taking into account the social and cultural aspects.

Like many other urban cities, the buildings in Egypt play a significant role in determining the environmental sustainability of the society. Investigation on the existing building environmental assessment methods in the world shows that the energy criteria is a key factor in the evaluation process. To express the assessment criteria unambiguously, a comprehensive definition of sustainability and building energy performance to suit local needs is important. Proper coordination of the requirements in the building energy codes and the environmental assessment scheme is needed. This study aimed at answering the question of can Egyptian energy standards help to maintain a quality indoor environment for residential buildings for existing and new urban communities. This study explores the current situation, with a preliminary analysis of how EECRB may not be able to deliver its 'sustainable energy standards' goals due to missed or 
neglected measures, and more comprehensive guidelines should be given to designers to ensure the delivery of sustainable buildings is not hampered whilst also failing to meet energy standard goals. The study has shown that at present, the existing building energy codes in Egypt are prescriptive in nature. To provide greater design flexibility and encourage innovative design, it is important to move towards performance-based approach and consider the integrated whole building performance in the design and evaluation. To obtain these advantages in the environmental sustainability assessment of buildings, further efforts are needed to integrate the requirements of building energy codes and the performance concept into the sustainability assessment process. This will help to strengthen the technical base of and confidence with the assessment method in Egypt.

\section{REFERENCE}

1. Al-Hassan, A. (2009). The Introduction of Code of Sustainable Homes for the UK; Potentials and Problems. FORUM Ejournal, Newcastle University(9), 49-62.

2. Ayyad, K. M., \& Gabr, M. (2012). Greening Building Codes in Egypt. Paper presented at the Sustainable Futures: Architecture and Urbanism in the Global South, Kampala, Uganda.

3. Baniassadi, A., Heusinger, J., \& Sailor, D. J. (2018). Energy efficiency vs resiliency to extreme heat and power outages: The role of evolving building energy codes. Building and Environment, 139, 86-94. doi: https://doi.org/10.1016/j.buildenv.2018.05.024

4. BRE. (2010). Code for Sustainable Homes: Technical Guide. London, UK: Communities and Local Government.

5. Chan, A. L. S. (2018). Evaluating the impact of photovoltaic systems on the thermal performance of buildings and its implication to building energy code. A case study in subtropical Hong Kong. Energy Policy, 119, 674-688. doi: https://doi.org/10.1016/j.enpol.2018.04.041

6. Enker, R. A., \& Morrison, G. M. (2017). Analysis of the transition effects of building codes and regulations on the emergence of a low carbon residential building sector. Energy and Buildings, 156, 40-50. doi: https://doi.org/10.1016/j.enbuild.2017.09.059

7. Evans, M., Roshchanka, V., \& Graham, P. (2017). An international survey of building energy codes and their implementation. Journal of Cleaner Production, 158, 382-389. doi: https://doi.org/10.1016/j.jclepro.2017.01.007

8. Evans, M., Yu, S., Staniszewski, A., Jin, L., \& Denysenko, A. (2018). The international implications of national and local coordination on building energy codes: Case studies in six cities. Journal of Cleaner Production, 191, 127-134. doi: https://doi.org/10.1016/j.jclepro.2018.04.142

9. Ganah, A., Henderson, C., \& John, G. (2015). Feasibility of CSH in Assisting the New Housing Sector in Delivering Zero Carbon Homes by 2016. Procedia Engineering, 118, 1000-1007. doi: https://doi.org/10.1016/j.proeng.2015.08.541

10. Hanna, G. B. (2004). Residential Energy Code for New Buildings in Egypt. Paper presented at the CIB World Building Congress, Building for the Future, Toronto, Canada.

11. Hanna, G. B. (2013). Sustainable Energy Potential in the Egyptian Residential Sector. Journal of Environmental Science and Engineering, 2, 374-382.

12. Hanna, G. B. (2015). Energy Efficiency Building Codes and Green Pyramid Rating System. In A. Sayigh (Ed.), Renewable Energy in the Service of Mankind (Vol. 1): World Renewable Energy Congress, Brighton, United Kingdom of Great Britain and Northern Ireland.

13. HBNRC. (2007). The Egyptian Code of Energy Efficient buildings (Part 1- Residential Buildings) Cairo, Egypt: Housing and Building National Research Centre

14. McManus, A., Gaterell, M. R., \& Coates, L. E. (2010). The potential of the Code for Sustainable Homes to deliver genuine 'sustainable energy' in the UK social housing sector. Energy Policy, 38(4), 2013-2019. doi: https://doi.org/10.1016/j.enpol.2009.12.002 
15. Neven, L., Walker, G., \& Brown, S. (2015). Sustainable thermal technologies and care homes: Productive alignment or risky investment? Energy Policy, 84, 195-203. doi: https://doi.org/10.1016/j.enpol.2014.11.027

16. O’Malley, C., Piroozfar, P. A. E., Farr, E. R. P., \& Gates, J. (2014). Evaluating the Efficacy of BREEAM Code for Sustainable Homes (CSH): A Cross-sectional Study. Energy Procedia, 62, 210-219. doi: https://doi.org/10.1016/j.egypro.2014.12.382

17. Sheta, W., \& Sharples, S. (2010). Thermal Assessment of Dwellings in a New Community around Cairo. Paper presented at the CLIMA 2010, Antalya, Turkey.

18. Young, R. (2014). Global Approaches: A Comparison of Building Energy Codes in 15 Countries. ACEEE Summer Study on Energy Efficiency in Buildings. 